\title{
Effects of Iron Supplementation on Attention Deficit Hyperactivity Disorder in Children Treated with Methylphenidate
}

\author{
Sepehr Tohidi ${ }^{1, *}$, Elham Bidabadi ${ }^{2, *}$, Mohammad-Javad Khosousi ${ }^{3}$, Melika Amoukhteh $^{2}$, Maryam Kousha ${ }^{4}$, \\ Parham Mashouf ${ }^{5}$, Tamkin Shahraki ${ }^{2}$ \\ ${ }^{1}$ Student Research Committee, School of Medicine, Guilan Universtiy of Medical Sciences, ${ }^{2}$ Pediatric Diseases Research Center, Guilan University \\ of Medical Sciences, ${ }^{3}$ Gastrointestinal and Liver Diseases Research Center, Guilan University of Medical Sciences, ${ }^{4}$ Department of Psychiatry, \\ Shafa Hospital, Guilan University of Medical Sciences, ${ }^{5}$ Emergency Department, Arya Hospital, Rasht, Iran
}

\begin{abstract}
Objective: To evaluate the effect of iron on the attention deficit hyperactivity disorder, treated with methylphenidate. Methods: This double-blind, randomized placebo-controlled clinical trial was performed on 50 children with attention deficit hyperactivity disorder under the treatment of methylphenidate, with ferritin levels below $30 \mathrm{ng} / \mathrm{ml}$ and absence of anemia. They were randomly assigned into two groups of ferrous sulfate and placebo, for 12 weeks. Conners' Parent Rating Scale (CPRS) was used to assess the outcome in the first, sixth, and twelfth weeks.

Results: Almost all CPRS subscales improved in the ferrous sulfate group from the baseline to the endpoint, although only the changes in conduct subscale scores were significant $(p=0.003)$. There was no significant difference in score changes between two groups in intergroup comparison. Also, the score of learning problems $(p=0.007)$ in the first six weeks, and conduct $(p=0.023)$ and psychosomatic $(p=0.018)$ subscales in the second six weeks were improved in the ferrous sulfate group compared with the placebo group.

Conclusion: Our study showed promising effects of iron supplementation in the improvement of subscales of the CPRS.
\end{abstract}

KEY WORDS: Attention deficit disorder with hyperactivity; Iron; Child; Methylphenidate.

\section{INTRODUCTION}

Attention deficit hyperactivity disorder (ADHD) is a neurobiological syndrome defined as a persistent pattern of inattention/hyperactivity and impulsive behaviors [1,2] which affects 4 to $12 \%$ of school-aged children [3], and can lead to anxiety and depression during adulthood, if left untreated [4]. The prevalence rate of this disorder is higher in children than adults, it affects males more than females, however this ratio seems to be balanced in adulthood [5,6]. Moreover, the highest prevalence of ADHD has been reported in South America, Africa, and Oceania [7].

Received: November 4, 2020 / Revised: January 7, 2021

Accepted: June 27, 2021

Address for correspondence: Elham Bidabadi

Pediatric Diseases Research Center, Guilan University of Medical

Sciences, Namjoo Street, Siadati Avenue, Rasht, Iran

E-mail: bidabadi@gmail.com

ORCID: https://orcid.org/0000-0002-1067-3335

*These authors contributed equally to this study.
Children with ADHD may experience major functional impairments such as academic failure, weakness in communication with family members, antisocial behaviors, and lack of self-esteem [8]. ADHD has also been associated with high activity in cradles, lack of sleep, and abundant crying in infancy. The most common characteristics of ADHD are attention deficit, hyperactivity, selfperceived motor incompetence, emotional instability, distraction, impulsivity, memory, thinking, learning disabilities, aggressive behavior, and disobedience $[9,10]$.

The pathophysiology of ADHD is very complicated and its etiology is not well understood. Recent findings support multifactorial hypotheses; it is thought that the cause of ADHD, like other neuropsychological disorders, is a combination of genetics and environmental factors [11-16].

ADHD is usually treated with medication and its first and the most commonly used treatment is methylphenidate; however, various studies have reported that psychiatric intervention is also required [1,17-23]. Clinical

(c) This is an Open-Access article distributed under the terms of the Creative Commons Attribution Non-Commercial License (http://creativecommons.org/licenses/by-nc/4.0) which permits unrestricted non-commercial use, distribution, and reproduction in any medium, provided the original work is properly cited. 
and laboratory studies have shown the potential role of iron deficiency in the pathophysiology of ADHD. Iron deficiency is generally associated with attention and behavioral problems [24]. Prospective studies in children with iron deficiency anemia have shown socio-emotional and educational damages. Children with iron deficiency (with or without anemia) are involved in many cognitive problems including decreased IQ, motor, spatial memory, and selective attention problems, which can last for years $[25,26]$. Low iron concentration is associated with changes in myelin structure, followed by changes in cortical fibers function, and dopaminergic system. Iron is a tyrosine hydroxylase coenzyme that is involved in the synthesis of dopamine and is related to amino-oxidase activity, which is a dopamine reducer $[27,28]$. Dopamine is known as a key element in the pathogenesis of ADHD. Therefore, iron storage in the brain may be effective on dopamine-dependent functions and ADHD symptoms $[29,30]$.

Even though serum ferritin levels are associated with ADHD susceptibility [31], the use of iron as complementary medicine in improving symptoms of this disorder needs further investigation, especially despite contradictory results. The present study evaluated the effects of iron supplementation (ferrous sulfate) on the symptoms of children with $\mathrm{ADHD}$, treated with methylphenidate.

\section{METHODS}

\section{Patients}

This is a randomized double-blind clinical trial with placebo-control; Fifty-four patients assessed for eligibility, 3 of them excluded (do not fulfill inclusion criteria) and one did not follow the protocol, finally it was performed on 50 children with ADHD, aged 5 to 15 years old, who were referred to the child psychiatric clinic of Rasht Shafa Hospital.

All participants were enrolled by a child and adolescent expert psychiatrist and under the treatment of methylphenidate, with associated ferritin levels below $30 \mathrm{ng} / \mathrm{ml}$ and absence of anemia (defined as hemoglobin levels less than $11 \mathrm{~g} / \mathrm{dl}$ ). ADHD was diagnosed by diagnostic interview of the corresponding psychiatrist and based on the clinical criteria of Diagnostic and Statistical Manual of Mental Disorders 4th edition, text revision (DSM-IV-TR) [32]. It is necessary to mention that all patients were under the treatment of short-acting form of methylphenidate (Ritalin-by Novartis Pharmaceuticals Corporation) and methylphenidate was matched in both groups in terms of dosage and duration, before entering the study. The treatment in almost all patients were started as soon as they were diagnosed and the dose of methylphenidate had started with $0.3 \mathrm{mg} / \mathrm{kg} /$ dose and titrated to the optimal dose that was $20 \mathrm{mg} /$ day in most cases in the time of the study.

Children with mental disorders along with ADHD, severe chronic medical conditions (i.e., malnutrition), mental retardation and other psychiatric comorbidities (such as anxiety; by diagnostic interview of an expert psychiatrist and according to DSM-IV), inflammation or infection, taking medications other than methylphenidate including catecholamines, use of iron supplementation over the past three months, having contraindication of iron supplementation, severe fever (due to the false increase in the level of ferritin), and hypothyroidism were excluded from the study.

The whole study process was under the Helsinki Declaration with parental informed consent for participation in the study was obtained from them. Ethic Committee of Guilan University of Medical Sciences approved this study (no. IRCT201212012269N2).

\section{Procedure}

Baseline characteristics such as sex, age, height, duration of disease, family history, and other comorbidities of all subjects were recorded in a prepared proforma.

Patients were randomly assigned into two groups (Random Allocation Blocks). The first group received iron supplementation (ferrous sulfate $300 \mathrm{mg}$ capsule containing $80 \mathrm{mg}$ of elemental iron) and the second group received placebo, for 12 weeks. All subjects took a capsule daily in the morning. Placebos were designed by an expert pharmacologist as starch-containing capsules with exactly similar face to ferrous sulfate. Furthermore, both psychiatrists and patients' parents were uninformed of which ferrous sulfate or placebo patients were taking.

Iron status and patients' laboratory data, including Complete Blood Count, ferritin, serum iron, and Total Iron Binding Capacity (TIBC) were measured at the beginning of the study and at the 12th week.

All patients' parents were asked to fulfill the Conners' Parent Rating Scale (CPRS) questionnaire in the first, sixth, 
and twelfth weeks after medication to assess the possible early changes of CPRS scores and final outcome. In addition to the mentioned visits, patients were regularly visited every two weeks all over the study, for possible side effects of the drugs, checking vital signs and assessing the compliance of treatment.

\section{Instrument}

To assess the outcome, CPRS questionnaire [33] was applied for all subjects, a 48-items questionnaire that employed a 4-point Likert scale. Higher score in this measure indicate higher severity of the disease. This questionnaire provides a qualitative and quantitative assessment of attention deficit hyperactivity symptoms on five different subscales including conduct problems, learning problems, psychosomatic, impulsive-hyperactive, and anxiety. It also contains Hyperactivity Index ( $\mathrm{HI})$ which is more sensitive to demonstrate the treatment effect. It was completed by parents in the first, sixth, and twelfth weeks.

\section{Statistical Analysis}

The distribution of quantitative variables was estimated using the Shapiro-Wilks test. To compare the quantitative variables between the groups, independent $t$ test, and Paired test were used for the data with normal distribution and Mann-Whitney and Wilcoxon for the data with non-normal distribution. Pearson chi-square was used to measure qualitative variables. The percentage of changes in the severity of symptoms, based on the Conner's score, was evaluated by the Wilcoxon test for intra-group comparison and by the Mann-Whitney test for inter-group comparison. All statistical analyses were done by the program SPSS software version 19 for Windows (IBM Co., Armonk, NY, USA). $p$ values less than 0.05 were considered significant.

\section{RESULTS}

There were $48(87.8 \%)$ males and $2(12.2 \%)$ females, with the mean age of 8.42 years who met the inclusion criteria and randomly enrolled in two groups of 25 .

Demographic data, laboratory findings and CPRS results of subjects at the baseline are shown in Table 1. Although, no remarkable side effects were seen, but 3 patients in ferrous sulfate and 6 in the placebo group dropped out of the study. In ferrous sulfate group one was dis-

Table 1. Sample characteristics at the baseline

\begin{tabular}{|c|c|c|c|}
\hline Characteristics & $\begin{array}{l}\text { Ferrous sulfate } \\
\quad(n=25)\end{array}$ & $\begin{array}{l}\text { Placebo } \\
(n=25)\end{array}$ & $p$ value \\
\hline Age (yr) & $8.09 \pm 2.16$ & $8.75 \pm 3.09$ & 0.470 \\
\hline Male sex & $25(100)$ & $23(92)$ & 0.088 \\
\hline Height $(\mathrm{cm})$ & $124.82 \pm 8.68$ & $122 \pm 27.07$ & 0.693 \\
\hline Weight (kg) & $28.18 \pm 7.06$ & $37.13 \pm 24.04$ & 0.052 \\
\hline Duration of disease (yr) & $2.49 \pm 2.25$ & $4.19 \pm 3.29$ & 0.087 \\
\hline Family history of psychiatric disorders & & & 0.401 \\
\hline Negative & $17(68)$ & $17(68)$ & \\
\hline First degree & $6(24)$ & $6(24)$ & \\
\hline Second degree & $2(8)$ & $2(8)$ & \\
\hline Comorbidities & & & 0.058 \\
\hline Negative & $21(84)$ & $19(76)$ & \\
\hline Asthma & $4(16)$ & $4(16)$ & \\
\hline Glucose-6-phosphate dehydrogenase deficiency & $0(0)$ & $2(8)$ & \\
\hline Methylphenidate dose $(\mathrm{mg} / \mathrm{d})^{\mathrm{a}}$ & $20.45 \pm 4.06$ & $20.94 \pm 4.55$ & 0.910 \\
\hline \multicolumn{4}{|l|}{ Hematological values } \\
\hline Hemoglobin (g/dl) & $12.38 \pm 0.78$ & $13.08 \pm 1.30$ & 0.065 \\
\hline Mean cell volume $(\mathrm{fL})$ & $68.14 \pm 17.57$ & $73.03 \pm 15.01$ & 0.375 \\
\hline Serum iron $(\mu \mathrm{g} / \mathrm{dl})$ & $57.36 \pm 22.49$ & $77.50 \pm 35.61$ & 0.058 \\
\hline Serum ferritin $(\mathrm{ng} / \mathrm{ml})$ & $20.66 \pm 7.59$ & $21.09 \pm 6.33$ & 0.857 \\
\hline Total iron binding capacity ( $\mu \mathrm{g} / \mathrm{dl})$ & $356.81 \pm 29.49$ & $347 \pm 22.70$ & 0.273 \\
\hline
\end{tabular}

Values are presented as mean \pm standard deviation or number (\%).

${ }^{a}$ Almost all patients were under the treatment of psychostimulant as soon as they were diagnosed, with $0.3 \mathrm{mg} / \mathrm{kg} / \mathrm{dose}$ and titrated to the optimal dose, that was $20 \mathrm{mg} / \mathrm{d}$ in most cases. 
continued because of constipation and nausea and 2 were dropped out not due to any medical reasons. In placebo group, 3 patients were dropped out due to the same reason. There was no significant difference in dropouts from the completers in terms of age, sex, and severity of symptoms.

Serum ferritin levels in ferrous sulfate group increased from $20.66 \pm 7.59 \mathrm{ng} / \mathrm{ml}$ at the baseline to $46.86 \pm 25.53$ $\mathrm{ng} / \mathrm{ml}$ at the twelfth week, which was significantly more than the placebo group, from $21.09 \pm 6.33$ to $32.14 \pm$ $9.37 \mathrm{ng} / \mathrm{ml}(p=0.007)$. Iron status changes in both groups, from baseline to the 12th week, are shown in Table 2.

At the beginning of the project, most of the subscales of the CPRS had no significant clinical difference between the two groups; only the mean score of the psychosomatic subscale had a statistically significant difference between the groups $(p=0.038)$. The $\mathrm{HI}$ score had also no significant difference between the groups ( $p=0.903)$.

In the sixth week, only the mean score of the psychosomatic subscale had a significant difference between the groups ( $p=0.008$ ). The two groups had no significant difference in $\mathrm{HI}$ scores $(p=0.460)$.

In the twelfth week, the mean score of conduct problems subscale had a significant difference between the groups $(p=0.012)$. The $\mathrm{HI}$ scores had no significant difference between the two groups $(p=0.401)$. The compar-

Table 2. Effect of treatment on Hematological values from baseline to endpoint at 12 weeks

\begin{tabular}{|c|c|c|c|c|c|}
\hline \multirow{2}{*}{ Hematological values } & \multicolumn{2}{|c|}{ Ferrous sulfate $(n=22)$} & \multicolumn{2}{|c|}{ Placebo $(\mathrm{n}=19)$} & \multirow{2}{*}{$p$ value } \\
\hline & Mean \pm SD & $95 \% \mathrm{Cl}$ & Mean \pm SD & $95 \% \mathrm{Cl}$ & \\
\hline Hemoglobin (g/dl) & $-0.5 \pm 1.30$ & -0.62 to 0.53 & $1.13 \pm 1.18$ & 0.44 to 1.81 & 0.037 \\
\hline Mean cell volume (fL) & $-10.46 \pm 16.17$ & -17.63 to -3.29 & $3.91 \pm 10.69$ & -2.26 to 10.09 & 0.001 \\
\hline Serum iron $(\mu \mathrm{g} / \mathrm{dl})$ & $-31.36 \pm 33.01$ & -46.00 to -17.73 & $4.14 \pm 21.05$ & -8.01 to 16.29 & 0.001 \\
\hline Serum ferritin $(\mathrm{ng} / \mathrm{ml})$ & $-26.20 \pm 20.45$ & -35.26 to -17.13 & $11.05 \pm 5.97$ & -14.23 to -7.87 & 0.007 \\
\hline Total iron binding capacity ( $\mu \mathrm{g} / \mathrm{dl})$ & $23.45 \pm 20.52$ & 14.36 to 32.55 & $4.38 \pm 21.65$ & 15.91 to 7.16 & 0.000 \\
\hline
\end{tabular}

$\mathrm{SD}$, standard deviation $\mathrm{Cl}$, confidence interval.

Table 3. Comparison of mean CPRS subscales' scores from baseline to the endpoint at 12th week

\begin{tabular}{|c|c|c|c|c|c|}
\hline \multirow{2}{*}{ CPRS subscales } & \multicolumn{2}{|c|}{ Ferrous sulfate $(n=22)$} & \multicolumn{2}{|c|}{ Placebo $(n=19)$} & \multirow{2}{*}{$p$ value } \\
\hline & Mean \pm SD & $95 \% \mathrm{Cl}$ & Mean \pm SD & $95 \% \mathrm{Cl}$ & \\
\hline \multicolumn{6}{|l|}{ Week 1} \\
\hline Conduct & $64.91 \pm 11.38$ & $59.87-65.95$ & $69.14 \pm 12.97$ & $61.66-76.63$ & 0.310 \\
\hline Learning & $64.82 \pm 14.56$ & $58.36-71.27$ & $61.29 \pm 8.18$ & $56.56-66.01$ & 0.415 \\
\hline Psychosomatic & $63.73 \pm 20.19$ & $54.78-72.68$ & $50.71 \pm 12.46$ & $43.52-57.91$ & 0.038 \\
\hline Hyperactivity/irritability & $64.73 \pm 9.53$ & $60.50-68.95$ & $62.00 \pm 9.72$ & $56.39-67.61$ & 0.412 \\
\hline Anxiety & $54.64 \pm 8.27$ & $50.97-58.30$ & $52.86 \pm 5.59$ & $49.63-56.08$ & 0.484 \\
\hline Hyperactivity index & $64.55 \pm 9.86$ & $60.17-68.92$ & $64.14 \pm 9.09$ & $58.90-69.39$ & 0.903 \\
\hline \multicolumn{6}{|l|}{ Week 6} \\
\hline Conduct & $62.00 \pm 12.28$ & $56.55-67.45$ & $63.50 \pm 8.05$ & $59.21-67.79$ & 0.673 \\
\hline Learning & $60.73 \pm 15.33$ & $53.93-67.53$ & $64.38 \pm 6.39$ & $60.97-67.78$ & 0.377 \\
\hline Psychosomatic & $68.27 \pm 20.20$ & $59.31-77.23$ & $52.38 \pm 11.82$ & $46.08-58.67$ & 0.008 \\
\hline Hyperactivity/irritability & $59.55 \pm 8.66$ & $55.71-63.38$ & $58.25 \pm 8.77$ & $53.57-62.93$ & 0.652 \\
\hline Anxiety & $53.27 \pm 6.30$ & $50.48-56.06$ & $54.50 \pm 7.10$ & $50.72-58.28$ & 0.577 \\
\hline Hyperactivity index & $61.00 \pm 9.62$ & $56.73-65.27$ & $63.13 \pm 7.11$ & $59.34-64.91$ & 0.460 \\
\hline \multicolumn{6}{|l|}{ Week 12} \\
\hline Conduct & $56.64 \pm 9.19$ & $52.56-60.71$ & $66.63 \pm 14.12$ & $59.10-74.15$ & 0.012 \\
\hline Learning & $62.73 \pm 15.98$ & $55.64-69.81$ & $62.25 \pm 16.02$ & $53.71-70.79$ & 0.928 \\
\hline Psychosomatic & $57.80 \pm 16.73$ & $49.15-68.10$ & $58.63 \pm 17.78$ & $57.39-65.52$ & 0.887 \\
\hline Hyperactivity/irritability & $61.45 \pm 9.17$ & $57.39-65.52$ & $62.13 \pm 11.18$ & $56.17-68.08$ & 0.840 \\
\hline Anxiety & $55.91 \pm 9.57$ & $51.67-60.15$ & $52.13 \pm 5.52$ & $49.18-55.07$ & 0.165 \\
\hline Hyperactivity index & $63.00 \pm 9.90$ & $58.61-67.39$ & $66.25 \pm 13.72$ & $58.94-73.56$ & 0.401 \\
\hline
\end{tabular}

CPRS, Conners' Parent Rating Scale; SD, standard deviation; $\mathrm{Cl}$, confidence interval. 
ison of mean CPRS subscales' scores from baseline to the endpoint at 12th week is shown in Table 3.

To examine the trend of changes in the mean CPRS subscales' scores within the groups and between the groups, the percent change of scores were evaluated. The results are shown in Table 4. From the baseline to the sixth week after taking ferrous sulfate/placebo, the scores in conduct subscale problems of the placebo group $(p=0.012)$, and Hyperactivity/irritability subscale problems of both groups ( $p=0.034$ in ferrous sulfate, $p=0.049$ in placebo) were improved significantly. The learning subscale score in the placebo group was declined significantly ( $p=$ 0.012). In the comparison of score changes between the groups, only the changes in the mean score of learning problems subscale were significantly different between the two groups (improved in the ferrous sulfate group compared with the placebo group, $p=0.007$ ). There was no other significant difference in score changes of other subscales and $\mathrm{HI}$ in both intragroup and intergroup comparison in this period.
From the sixth to twelfth week after taking the ferrous sulfate/placebo, the mean scores of conduct and psychosomatic subscale in the ferrous sulfate group were improved significantly ( $p=0.030$ and $p=0.050$, respectively). Additionally, the score of the psychosomatic subscale in the placebo group was declined significantly $(p=0.021)$. In the comparison of score changes between the groups, the changes in mean scores of conduct ( $p=$ $0.023)$ and psychosomatic $(p=0.018)$ subscales were significantly different between the two groups (improved in the ferrous sulfate group compared with the placebo group). There was no other significant difference in score changes of other subscales and $\mathrm{HI}$ in both intragroup and intergroup comparison in this period.

From the baseline to the 12th week almost all CPRS subscales improved in the ferrous sulfate group, and only the changes in conduct subscale scores were significant ( $p=0.003)$. In intergroup comparison, there was no significant difference in score changes between two groups in none of CPRS subscales and HI.

Table 4. The effect of treatment on the percentage change ${ }^{\mathrm{a}}$ of the mean CPRS subscales' scores from baseline to the endpoint

\begin{tabular}{|c|c|c|c|c|c|c|c|}
\hline \multirow{2}{*}{ CPRS subscales } & \multicolumn{3}{|c|}{ Ferrous sulfate $(n=22)$} & \multicolumn{3}{|c|}{ Placebo $(n=19)$} & \multirow{2}{*}{$p$ value } \\
\hline & Mean \pm SD & $95 \% \mathrm{Cl}$ & $p$ value $^{\mathrm{b}}$ & Mean \pm SD & $95 \% \mathrm{Cl}$ & $p$ value $^{\mathrm{b}}$ & \\
\hline \multicolumn{8}{|l|}{ Week $1-6$} \\
\hline Conduct & $-2.94 \pm 19.42$ & -11.55 to 5.67 & 0.228 & $-6.17 \pm 7.46$ & -10.48 to -1.86 & 0.012 & 0.396 \\
\hline Learning & $-5.35 \pm 15.65$ & -12.29 to 1.59 & 0.085 & $7.59 \pm 9.76$ & 1.96 to 13.23 & 0.012 & 0.007 \\
\hline Psychosomatic & $9.95 \pm 25.83$ & -1.5 to 21.41 & 0.193 & $11.63 \pm 35.97$ & -9.14 to 32.40 & 0.673 & 0.895 \\
\hline Hyperactivity/irritability & $-6.89 \pm 13.61$ & -12.92 to 7.95 & 0.034 & $-7.66 \pm 15.30$ & -16.50 to 1.17 & 0.049 & 0.412 \\
\hline Anxiety & $-1.60 \pm 9.83$ & -5.96 to 2.76 & 0.240 & $1.48 \pm 11.61$ & -5.22 to 8.18 & 0.794 & 0.360 \\
\hline Hyperactivity index & $-3.94 \pm 17.56$ & -11.73 to 3.84 & 0.202 & $-2.20 \pm 9.22$ & -7.52 to 3.13 & 0.424 & 0.948 \\
\hline \multicolumn{8}{|l|}{ Week 6-12 } \\
\hline Conduct & $-8.08 \pm 15.69$ & -10.48 to -1.86 & 0.030 & $6.57 \pm 15.50$ & -2.38 to 15.52 & 0.324 & 0.023 \\
\hline Learning & $2.85 \pm 18.29$ & -5.26 to 10.96 & 0.585 & $-6.57 \pm 20.34$ & -18.31 to 5.17 & 0.360 & 0.268 \\
\hline Psychosomatic & $-15.46 \pm 31.91$ & -30.40 to -0.53 & 0.050 & $10.40 \pm 19.76$ & -1.01 to 21.81 & 0.021 & 0.018 \\
\hline Hyperactivity/irritability & $3.55 \pm 9.94$ & -0.86 to 7.95 & 0.122 & $7.45 \pm 14.48$ & -0.91 to 15.81 & 0.096 & 0.101 \\
\hline Anxiety & $4.05 \pm 10.95$ & -0.80 to 8.91 & 0.070 & $-3.32 \pm 17.40$ & -13.37 to 6.72 & 0.478 & 0.165 \\
\hline Hyperactivity index & $2.42 \pm 12.95$ & -3.32 to 8.16 & 0.078 & $5.36 \pm 17.09$ & -4.51 to 15.33 & 0.307 & 0.172 \\
\hline \multicolumn{8}{|l|}{ Week $1-12$} \\
\hline Conduct & $-11.02 \pm 15.42$ & -17.86 to 11.30 & 0.003 & $0.40 \pm 18.87$ & -10.49 to 11.30 & 0.825 & 0.151 \\
\hline Learning & $-2.51 \pm 16.02$ & -9.61 to 4.60 & 0.165 & $1.02 \pm 22.98$ & -12.24 to 14.29 & 0.812 & 0.363 \\
\hline Psychosomatic & $-5.59 \pm 23.13$ & -16.41 to 5.24 & 0.216 & $22.03 \pm 47.99$ & -5.68 to 45.84 & 0.167 & 0.119 \\
\hline Hyperactivity/irritability & $-3.34 \pm 17.62$ & -11.15 to 4.47 & 0.311 & $-0.22 \pm 18.14$ & -10.69 to 10.36 & 0.637 & 0.696 \\
\hline Anxiety & $2.45 \pm 9.61$ & -1.81 to 6.72 & 0.192 & $-1.84 \pm 13.18$ & -9.45 to 5.77 & 0.878 & 0.289 \\
\hline Hyperactivity index & $-1.52 \pm 14.27$ & -7.85 to 4.80 & 0.476 & $3.16 \pm 16.33$ & -6.27 to 12.59 & 0.430 & 0.153 \\
\hline
\end{tabular}

CPRS, Conners' Parent Rating Scale; SD, standard deviation; $\mathrm{Cl}$, confidence interval.

${ }^{a}$ Percentage change of the mean score (that represents the degree of change over time) were calculated by subtracting week 1 mean scores from week 6 , week 6 from week 12 and week 1 from week 12, thendivide by the first score and multiply the answer by 100 thus a negative score indicated an improvement in the scales (the higher scores indicate the high severity of the diseases). Intragroup comparison of the mean percentage change. 'Intergroup comparison of the mean percentage change. 
Generally, oral ferrous sulfate therapy was well tolerated in all patients. None of them had decreased appetite or adverse reactions. Constipation in 2 patients (9\%) and alternate abdominal pain in 3 patients $(13.6 \%)$ were reported, that were eliminated despite the constant use of ferrous sulfate during twelve weeks. Four patients (18.1\%) had increased appetite while taking ferrous sulfate capsules. In the placebo group, 4 patients (19.21\%) had gastrointestinal upset and abdominal pain and 2 patients $(10.5 \%)$ complained from an increased appetite. No case of constipation or other adverse reactions was found in placebo group. In addition, vital signs and weight had not any significant clinical changes in both groups, within twelve weeks.

\section{DISCUSSION}

Iron is an essential and effective ingredient in the formation of myelin sheaths, synthesis of transducers, and neuronal metabolism. It is a cofactor of many enzymes and involves in the structure and transportation of brain proteins. The most common micronutrient deficiency in the world is iron deficiency $[7,8]$. Iron deficiency leads to poor myelination of the nervous system and disruption in the metabolism of monoamines. These changes not only affect memory, learning abilities, and motor skills but also cause psychological and mental disorders, especially in children [11]. About 10 studies have indicated the lower serum ferritin levels in ADHD patients than healthy controls [24]. Studies of Adisetiyo et al. [34], Menegassi et al. [35], and Calarge et al. [36] revealed a difference in dietary calorie and iron intake in ADHD patients compared with non-ADHD subjects.

In the present study, 50 patients with ADHD and serum ferritin levels lower than $30 \mathrm{ng} / \mathrm{ml}$ met the inclusion criteria and randomly entered into two groups. After twelve weeks, as expected, all hematological values were improved significantly in the ferrous sulfate group. Similarly, in Konofal et al. [37] study which the serum ferritin levels increased from $29.1 \pm 17.6 \mathrm{ng} / \mathrm{ml}$ at baseline to $45.9 \pm$ $22.6 \mathrm{ng} / \mathrm{ml}$ at 4 th week and $55.7 \pm 20.4 \mathrm{ng} / \mathrm{ml}$ at twelfth week in the iron treatment group $(p<0.001)$.

In this clinical trial study twelfth week, the mean CPRS score of conduct problems in the ferrous sulfate group was significantly lower than the corresponding score in placebo $(p=0.012)$.
In the evaluation of score changes, many significant improvements appeared in different CPRS subscales of ferrous sulfate group in different periods (Hyperactivity/irritability in the first six weeks, conduct and psychosomatic in the second six weeks, and conduct subscale from baseline to the endpoint). The reason is unclear; it needs further investigations to explore the exact cause. In intergroup comparison, the score changes of learning subscale in the first six weeks, and the score changes of conduct and psychosomatic subscale in the second six weeks were significantly improved in the ferrous sulfate group compared with the placebo group. Additionally, all subscales of the CPRS (except anxiety) were improved in the ferrous sulfate group from the baseline to the endpoint, however not statistically significant. All these results support the hypothesis that Iron supplementation may help the improvement of ADHD symptoms especially in conduct subscale. It is crucial to mention that a larger sample size could have yielded more accurate results. Also, given that the CPRS score in conduct subscale had improvement in all periods and the corresponding improvement was significant in the evaluation of baseline to the endpoint, it is possible that iron and ferritin levels may play a role, specifically in the conduct problems, a subscale that is fairly indicative of some problems such as arrogance, irritability, bullying or threatening others, physical fights, stealing, hurting animals and humans. Therefore, further studies are needed to assess their possible role. There is not any significant difference between ferrous sulfate and placebo groups in other hematological values except the serum iron level, that showed a marginal difference in the Table 1, and it seems that the CPRS subscales improvements could not be affected by this marginal baseline difference. Besides, the trend of changes in CPRS subscales is evaluated in both intergroup and intragroup comparisons; Nevertheless, it is important to mention biased sample probability.

In a similar study by Konofal et al. [37], the CPRS total score improved more in the iron group $(-7.0 \pm 14.0, p=$ $0.055)$ than the placebo group $(-3.2 \pm 22.8, p=0.769)$. However, it didn't reach a significant level. The ADHD Rating Scale decreased significantly in the iron group after 12 weeks $(-10.2 \pm 14.0, p=0.008)$. In another study by Sever et al. [38], on 14 patients with ADHD, a significant decrease in the CPRS score (from $17.6 \pm 4.5$ to $12.7 \pm 5.4$ ) was found after thirty days of treatment with Ferocal 5 
$\mathrm{mg} / \mathrm{kg}$ daily. Both of these studies were almost in line with ours.

Tolerance of oral ferrous sulfate was well in our patients. The side effects in our study (constipation and transient abdominal pain) were favorable with those reported in similar previous studies $[30,37,38]$.

Our study had several limitations such as the small sample size of subjects, single assessment measure (CPRS) for assessing outcomes, lack of evaluation differences of iron on CPRS in different subtypes of ADHD and short duration of the study. On the other hand, it should be noted that serum ferritin may not represent iron levels in the brain. It is crucial to mention that the authors strongly believe that this study is a preliminary study. Therefore, further studies with larger sample size, longer follow up, multi assessment tool, and with more non-invasive methods, such as magnetic resonance imaging, to assess brain iron levels correctly is highly recommended. Moreover several factors, such as dietary intake and comorbidities, have an effect on the serum iron level, that were not completely considered in our study. It is considered that nutritional status, weight and body mass index are closely related to hemoglobin level in the growing period of children. Because in children with ADHD, weight is an important factor in determining the dose of psychostimulant, so it might be necessary to specify the dose of psychostimulant taken between the two groups.

In conclusion, this study showed the promising effects of iron supplementation in the improvement of subscales of the CPRS, and the learning problems within the first six weeks, conduct and psychosomatic problems within the 2nd six weeks, and conduct problems in the twelfth week after intervention were improved in the ferrous sulfate group compared with the placebo group. Almost all CPRS subscales had improvement from the baseline to the endpoint (although not significant). Therefore, all these results confirm the need for further investigations with larger sample size and longer follow-up. Oral ferrous sulfate therapy had no significant side effects in treated patients.

\section{Acknowledgments}

The authors thank all the parents and children who were coordinated in this research.

\section{- Conflicts of Interest}

No potential conflict of interest relevant to this article was reported.

\section{Author Contributions}

Conceptualization: Elham Bidabadi, Sepehr Tohidi, Maryam Kousha. Data acquisition: Sepehr Tohidi, Parham Mashouf, Mohammad-Javad Khosousi, Melika Amoukhteh. Formal analysis: Mohammad-Javad Khosousi, Melika Amoukhteh. Funding: Elham Bidabadi. Supervision: Elham Bidabadi, Maryam Kousha. Writing-original draft: Sepehr Tohidi, Parham Mashouf, Tamkin Shahraki. Writing-review \& editing: Elham Bidabadi, Parham Mashouf, Tamkin Shahraki.

\section{ORCID}

Sepehr Tohidi https://orcid.org/0000-0002-9987-5020

Elham Bidabadi http://orcid.org/0000-0002-1067-3335 Mohammad-Javad Khosousi https://orcid.org/0000-0002-2896-8094

Melika Amoukhteh https://orcid.org/0000-0003-3488-8960 Maryam Kousha https://orcid.org/0000-0002-8101-8258 Parham Mashouf https://orcid.org/0000-0002-0474-4600

Tamkin Shahraki https://orcid.org/0000-0001-6811-8951

\section{REFERENCES}

1. Geffen J, Forster K. Treatment of adult ADHD: a clinical perspective. Ther Adv Psychopharmacol 2018;8:25-32.

2. Mahone EM, Denckla MB. Attention-deficit/hyperactivity disorder: a historical neuropsychological perspective. I Int Neuropsychol Soc 2017;23:916-929.

3. Venkatesh C, Ravikumar T, Andal A, Virudhagirinathan BS. Attention-deficit/hyperactivity disorder in children: clinical profile and co-morbidity. Indian J Psychol Med 2012;34: 34-38.

4. Liebrenz M, Gamma A, Ivanov I, Buadze A, Eich D. Adult attention-deficit/hyperactivity disorder: associations between subtype and lifetime substance use - a clinical study. F1000Res 2015:4:407.

5. Thapar A, Cooper M. Attention deficit hyperactivity disorder. Lancet 2016;387:1240-1250.

6. Magnin E, Maurs C. Attention-deficit/hyperactivity disorder during adulthood. Rev Neurol (Paris) 2017;173:506-515.

7. Wang T, Liu K, Li Z, Xu Y, Liu Y, Shi W, et al. Prevalence of attention deficit/hyperactivity disorder among children and adolescents in China: a systematic review and meta-analysis. BMC Psychiatry 2017;17:32.

8. Singh A, Yeh CJ, Verma N, Das AK. Overview of attention deficit hyperactivity disorder in young children. Health Psychol Res 2015;3:2115.

9. Hamed AM, Kauer AJ, Stevens HE. Why the diagnosis of atten- 
tion deficit hyperactivity disorder matters. Front Psychiatry 2015;6:168.

10. Thapar A, Cooper M, Jefferies R, Stergiakouli E. What causes attention deficit hyperactivity disorder? Arch Dis Child 2012; 97:260-265.

11. Albrecht B, Uebel-von Sandersleben $\mathrm{H}$, Gevensleben $\mathrm{H}$, Rothenberger A. Pathophysiology of ADHD and associated problems-starting points for NF interventions? Front Hum Neurosci 2015;9:359.

12. Sharma A, Couture J. A review of the pathophysiology, etiology, and treatment of attention-deficit hyperactivity disorder (ADHD). Ann Pharmacother 2014;48:209-225.

13. Magnus W, Nazir S, Anilkumar AC, Shaban K. Attention deficit hyperactivity disorder (ADHD). Treasure Island:StatPearls Publishing LLC.;2020.

14. Kim KM, Kim JH, Kim D, Lim MH, Joo H, Yoo SJ, et al. Associations among high risk for sleep-disordered breathing, related risk factors, and attention deficit/hyperactivity symptoms in elementary school children. Clin Psychopharmacol Neurosci 2020;18:553-561.

15. Yazici KU, Yazici IP, Ustundag B. Increased serum hepcidin levels in children and adolescents with attention deficit hyperactivity disorder. Clin Psychopharmacol Neurosci 2019;17: 105-112.

16. Yoo SJ, Joo H, Kim D, Lim MH, Kim E, Ha M, et al. Associations between exposure to bisphenol $A$ and behavioral and cognitive function in children with attention-deficithyperactivity disorder: a case-control study. Clin Psychopharmacol Neurosci 2020;18:261-269.

17. Shier AC, Reichenbacher T, Ghuman HS, Ghuman JK. Pharmacological treatment of attention deficit hyperactivity disorder in children and adolescents: clinical strategies. J Cent Nerv Syst Dis 2012;5:1-17.

18. Wang SM, Han C, Lee SJ, Jun TY, Patkar AA, Masand PS, et al. Modafinil for the treatment of attention-deficit/hyperactivity disorder: a meta-analysis. J Psychiatr Res 2017;84:292-300.

19. Jung $C$, Choi S, Jeong S, Song C, Seo W, Chung US, et al. Multicenter, open-label study to evaluate the effects of methy/phenidate-OROS(Concerta ${ }^{\circledR}$ ) on cognitive functions in children with attention deficit hyperactivity disorder. Clin Psychopharmacol Neurosci 2007;5:31-37.

20. Fujioka T, Takiguchi S, Yatsuga C, Hiratani M, Hong KE, Shin MS, et al. Advanced test of attention in children with attention-deficit/hyperactivity disorder in Japan for evaluation of methylphenidate and atomoxetine effects. Clin Psychopharmacol Neurosci 2016;14:79-87.

21. Ozturk O, Alacam H, Basay BK, Basay O, Buber A, Ay Ol, et al. The effect of single dose methy/phenidate on neurometabolites according to COMT gene val158Met polymorphism in the patient with attention deficit hyperactivity disorder: a study using magnetic resonance spectroscopy. Clin Psychopharmacol Neurosci 2016;14:184-193.

22. Hong HJ, Hong N, Yoon HJ, Choi T, Lee S, Yook KH.
Differences in the clinical characteristics of remission and non-remission groups with once-daily OROS-methy/phenidate treatment of attention-deficit/hyperactivity disorder. Clin Psychopharmacol Neurosci 2008:6:24-30.

23. Ergür AT, Gül H, Gül A. Methy/phenidate and central precocious puberty: a probable side effect among seven children with the attention deficit hyperactivity disorder. Clin Psychopharmacol Neurosci 2019;17:446-449.

24. Wang Y, Huang L, Zhang L, Qu Y, Mu D. Iron status in attention-deficit/hyperactivity disorder: a systematic review and meta-analysis. PLoS One 2017;12:e0169145.

25. Islam K, Seth S, Saha S, Roy A, Das R, Datta AK. A study on association of iron deficiency with attention deficit hyperactivity disorder in a tertiary care center. Indian J Psychiatry 2018:60:131-134.

26. Tseng PT, Cheng YS, Yen CF, Chen YW, Stubbs B, Whiteley P, et al. Peripheral iron levels in children with attention-deficit hyperactivity disorder: a systematic review and meta-analysis. Sci Rep 2018;8:788.

27. Bener A, Kamal M, Bener H, Bhugra D. Higher prevalence of iron deficiency as strong predictor of attention deficit hyperactivity disorder in children. Ann Med Health Sci Res 2014;4(Supp/ 3):S291-S297.

28. Demirci K, Yildirim Baş F, Arslan B, Salman Z, Akpinar A, Demirdaş A. The investigation of symptoms and diagnoses of adult-attention deficit/hyperactivity disorder in women with iron deficiency anemia. Noro Psikiyatr Ars 2017;54:72-77.

29. Gold MS, Blum K, Oscar-Berman M, Braverman ER. Low dopamine function in attention deficit/hyperactivity disorder: should genotyping signify early diagnosis in children? Postgrad Med 2014; 126:153-177.

30. Panahandeh G, Vatani B, Safavi P, Khoshdel A. The effect of adding ferrous sulfate to methylphenidate on attention-deficit/hyperactivity disorder in children. J Adv Pharm Technol Res 2017;8:138-142.

31. Oner P, Oner O, Azik FM, Cop E, Munir KM. Ferritin and hyperactivity ratings in attention deficit hyperactivity disorder. Pediatr Int 2012;54:688-692.

32. Steinau S. Diagnostic criteria in attention deficit hyperactivity disorder- changes in DSM 5. Front Psychiatry 2013;4:49.

33. Gianarris WJ, Golden CJ, Greene L. The Conners' Parent Rating Scales: a critical review of the literature. Clin Psychol Rev 2001;21:1061-1093.

34. Adisetiyo V, Jensen JH, Tabesh A, Deardorff RL, Fieremans E, Di Martino A, et al. Multimodal MR imaging of brain iron in attention deficit hyperactivity disorder: a noninvasive biomarker that responds to psychostimulant treatment? Radiology 2014;272:524-532.

35. Menegassi M, Mello ED, Guimarães LR, Matte BC, Driemeier F, Pedroso GL, et al. Food intake and serum levels of iron in children and adolescents with attention-deficit/hyperactivity disorder. Braz I Psychiatry 2010;32:132-138.

36. Calarge C, Farmer C, DiSilvestro R, Arnold LE. Serum ferritin 
and amphetamine response in youth with attention-deficit/hyperactivity disorder. J Child Adolesc Psychopharmacol 2010;20:495-502.

37. Konofal E, Lecendreux M, Deron J, Marchand M, Cortese S, Zaïm $\mathrm{M}$, et al. Effects of iron supplementation on attention def- icit hyperactivity disorder in children. Pediatr Neurol 2008; 38:20-26.

38. Sever Y, Ashkenazi A, Tyano S, Weizman A. Iron treatment in children with attention deficit hyperactivity disorder. A preliminary report. Neuropsychobiology 1997;35:178-180. 